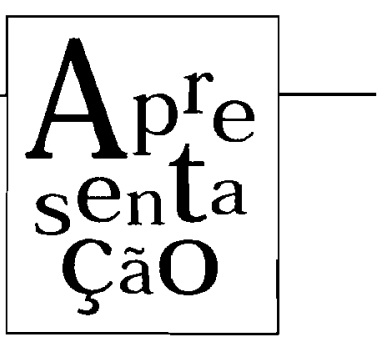

\title{
COMUNICAÇÃO/EDUCAÇÃO E TRANSDISCIPLINARIDADE: OS CAMINHOS DA LINGUAGEM
}

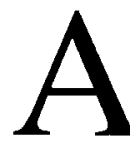

s fronteiras entre os campos de conhecimento tornaram-se fluidas. Embonente, formando novos campos, em outro patamar. Essa dialética entre intercâmbio e especificidade, entre totalidade e particular, num movimento que impede que as disciplinas se fechem em si mesmas e cada uma se considere a melhor, fragmentando a apreensão científica da realidade (que não é compartimentada), constitui a transdisciplinaridade, e é o grande desafio daqueles que se dispõem a refletir, criticar e construir uma nova variável histórica.

É nesse patamar que transitam questões básicas da contemporaneidade. Entre elas as da comunicação, incluindo as manifestações tecnológicas (rádio, TV, Internet etc.). Toda comunicação - mesmo os fatos que se transformam em notícia e que são divulgados para o mundo todo, instantaneamente, através da tecnologia, rompendo os conceitos de tempo e espaço com os quais sempre operamos - está baseada num discurso, construído no pólo do enunciador (pessoas, empresas, instituições), com o objetivo de persuadir, de convencer, de tornar único um ponto de vista, de transformar em verdade uma única interpretação histórica, sempre atendendo a objetivos que quase nunca contemplam a maioria.

\section{LINGUAGEM E COMUNICAÇÃO}

O discurso da comunicação se constrói com linguagem, sobretudo a linguagem verbal. Por isso, um dos caminhos privilegiados para seu estudo

\section{A AUTORA}

\section{Maria Aparecida Baccega}

Professora Livre-Docente do Departamento de Comunicações e Artes da ECA-USP. Coordenadora do curso Gestão de Processos Comunicacionais (lato sensu) e do Núcleo de Pesquisa de Telenovela (NPTN). 
está centrado no âmbito das ciências da linguagem, entendidas essas como parte das ciências sociais. Ou seja: a linguagem não serve apenas para "etiquetar" a realidade, confinando processos e fatos sociais em classificações estáticas. Cada signo, cada palavra transporta a carga de valores que aquela sociedade lhe atribuiu: "negro", por exemplo, terá tantos sentidos quantas são as numerosas modalidades de preconceito contra a raça negra que continuam a vigir no Brasil, apesar de um discurso oficial que néga essa realidade. Cada palavra materializa a prática social do grupo ou classe social que a utiliza e que a modifica permanentemente no seu cotidiano, a partir de suas vivências. Logo, os estudos de linguagem dialogam obrigatoriamente com Sociologia, Antropologia etc.

Alicerçada na linguagem com as características apontadas, temos a comunicação: seu suporte mais democrático é o aparelho fonador, que todo ser humano possui. Hoje, essa comunicação, graças ao avanço da tecnologia, amplificouse: podemos ver, na sala de nossa casa, o que está ocorrendo no Golfo Pérsico, por exemplo ou em Kossovo, ou na Albânia. Mas, o que vemos? Aquilo que foi selecionado para que víssemos e com os comentários e análises que nos levam a interpretar da maneira que nos é passado. Ou seja: além de selecionarem os fatos que podemos conhecer, selecionam também o ponto de vista a partir do qual vamos interpretá-los. É como se não existissem mediações, filtros a partir dos quais nos "contam" o mundo, aquilo que estamos "vendo"; como se a "verdade" fosse aquela, sem lugar para movimentos de interpretação. Nesse caso, é como se a linguagem apenas "etiquetasse" a realidade e o produto etiquetado nos fosse "vendido" como o melhor, o mais confiável, o único capaz de dar conta do que ocorre no mundo. Mundo formado, aliás, tão-somente por esses produtos previamente selecionados pelas empresas de comunicação para que os conhecêssemos e, mais que isso, como se o mundo fosse um bazar, com prateleiras, e os fatos, "etiquetados", fossem ocupando os lugares nessas prateleiras: as estantes do bem (manutenção do status quo) e as estantes do mal (contrários ao status $q u o$ ). Assim se estabelece o pensamento único, tão necessário para a manutenção da atual estrutura da sociedade.

\section{MEDIAÇÃO DA LINGUAGEM}

Esse discurso da comunicação, originado na palavra e em outras manifestações de linguagem, faz a mediação entre nós e o mundo. Então, se já havíamos afirmado que para estudar linguagem é preciso intercambiar com Sociologia e Antropologia, por exemplo (e é só a partir da inserção da linguagem nesse âmbito que ela entra nos estudos de comunicação), para estudar comunicação é preciso estabelecer um diálogo mais amplo, com mais saberes, que vão incluir Economia 
(a comunicação se faz por empresas e conglomerados de empresas), Física e Química (pelo modo de operar a comunicação na era tecnológica), além de muitas outras. Sem transdisciplinaridade, o estudo da comunicação não ocorre. "Tentar desvencilhar-se delas [as disciplinas], identificando a comunicação a uma disciplina, é reduzir o campo a uma parcela que, por mais rica que seja, não poderá nunca deixar de ser um empobrecimento deformante e uma usurpação"'.

\section{DISCURSO DA COMUNICAÇÃO: HISTÓRIA E LITERATURA}

É possível percorrer o campo da comunicação entrando pela porta das ciências da linguagem (entendidas no concerto das ciências sociais), ou seja, a linguagem como constitutiva da experiência e não como mero instrumento. $\mathrm{E}$, a partir daí, mostrar como o discurso da comunicação, com suas especificidades, é uma conjunção, com características próprias, dos discursos da história e da literatura.

O estudo do discurso da história deve permitir que se perceba como os fatos históricos são construções, resultado das mediações do historiador, as quais entram numa rede de relações que tece a história de determinado período, essa mesma rede também construída pelo historiador, que a desenvolve a partir de um lugar, o lugar do qual ele vê. O historiador, com seus condicionamentos, seleciona materiais históricos, escolhe as fontes, elabora fatos, reconstrói o passado, inscreve seu trabalho nas disputas de seu tempo. "O discurso da história é a manifestação, elaborada no presente, por um indivíduo/sujeito que, 'preso' a uma determinada formação ideológica/formação discursiva (no caso, a da história), debruça-se sobre o passado e, na condição de sujeito ativo nesse processo de conhecimento, vai articular de um determinado modo os fatos históricos, mostrando, nessa articulação, nesse enredamento, seu ponto de vista sobre a contemporaneidade e sua proposta de futuro"2.

O discurso da literatura é a outra face dessa mesma moeda: o discurso da comunicação. Preso à consciência estética, é o discurso das possibilidades humanas e não do efetivamente vivido. $O$ indivíduo/sujeito que produz literatura, tal como o que produz história, não é independente: "tem suas amarras nos condicionamentos da sociedade em que vive. É, porém, autônomo, ou seja, capaz de reelaborar essa carga, produzindo o novo"3.

Ambos os discursos - da história e da literatura - aproximam-se e distanciam-se em suas configurações. E, com tais características, formam o discurso da comunicação, que, selecionando e editando fatos, interpretando-os, atuando na

1. MARTÍN-BARBERO, Jesus. Prefácio. In: BACCEGA, M. A. Comunicação e linguagem. Discursos e ciência. São Paulo: Moderna, 1998.

2. BACCEGA, M. A. Comunicação... op. cit. p. 35.

3. BACCEGA, M. A. Comunicação... op. cit. p. 36. 
fronteira entre realidade e ficção, constroem o sentido do mundo em que vivemos. E o comunicador é o mediador entre a história e a literatura, entre a realidade e a ficção, construindo um discurso que, feito aparentemente "para ir-se embora", para esvair-se na edição do jornal ou no produto televisivo ou radiofônico, constitui-se, na verdade, num discurso que se mascara, apenas "preparando a hora de voltar". Voltar sem nunca ter partido, pois é ele, na verdade, como dissemos, que constrói os sentidos do mundo e que vem governando nossa percepção da realidade.

\section{ESCOLA, COMUNICAÇÃO/EDUCAÇÃO, TRANSDISCIPLINARIDADE}

A Escola, ressignificada, é chamada mais uma vez, e sempre, para, no bojo dessa realidade, apontar caminhos de democratização. Um desses caminhos passa pela distinção entre a informação, fragmentada, tal qual veiculada pelos meios de comunicação, e o conhecimento, totalidade que implica a "reelaboração do que está; inclui a condição de ser capaz de trazer à superfície o que é ainda virtual naquele domínio. Prevê ter claro que o virtual de um domínio nada mais é que o resultado da interdiscursividade de todos os domínios, possível naquela formação social; que os diversos fenômenos da vida são concatenados em referência à sociedade como um todo. Para tanto, as informações fragmentadas não são suficientes"4. E essa inter-relação só é possível pela transdisciplinaridade.

Com isso já estamos no campo da comunicação/educação. Nele circulam essas "situações novas que encontraram sua expressão teórica mais avançada em uma compreensão da cultura como configuração histórica dos processos e das práticas comunicativas. Essas que necessitam, mais do que nunca, articular os saberes quantitativos a um conhecimento qualitativo capaz de decifrar a produção comunicativa de sentido, toda a trama de discursos que ela mobiliza, de subjetividades e de contextos, em um mundo de tecnologias midiáticas, cada dia mais densamente incorporadas à cotidianidade dos sujeitos e cada dia mais descaradamente excludentes dos direitos das maiorias à voz e ao grito, à palavra e à canção"s.

Este número da revista Comunicação \& Educação apresenta mais algumas características do campo comunicação/educação.

\section{ARTIGOS NACIONAIS}

Maria Cristina Castilho Costa, em seu artigo Sociedade informacional, toma como ponto de partida a relação individual com a máquina computador para desfi- 
lar o histórico dessas tecnologias, com sua contextualização sociopolítica. E alerta: "quando apertamos o botão power de nosso PC, não nos damos conta de que passamos a integrar uma rede infinita de relações da qual participamos, até então, como meros usuários. Uma rede que se distribui pela administração pública e privada, pelo mercado e pelas comunicações e da qual fazemos parte sem que tenhamos consciência".

E como posicionar-se diante dessa realidade, com consciência? "Como o educador deve se posicionar frente às novas práticas do olhar que cruzam as práticas escolares, sem incorrer no viés da postura que apenas resvala na substituição da oralidade do professor pela verbo-visualidade técnica, mediada pela televisão e pelo computador?" Armando Martins de Barros discute a questão em Tratamento das imagens na formação do pedagogo.

Educar o olhar possibilita a recepção crítica, inclusive de programas de televisão. É o que Vânia Lúcia Quintão Carneiro vem apresentar em Programas educativos na $T V$, em que, a partir de um amplo quadro de referências sobre programas educativos na/da TV, a autora analisa o programa Castelo Rá-Tim-Bum, da TV Cultura.

Também "é preciso recriar o espaço público a partir do fenômeno da globalização, que faz próximo o distante e distante o próximo", alerta Luís Roberto Alves. "Na sociedade denominada midiática e globalizada mais se confirma a asserção: se não é mais hora de nos agarrarmos ao Estado-muleta ou Estado-suporte, é hora de recriá-lo a partir de nova base de valores, que não se bastam nem se sustentam na privatização da esfera pública”. Essa, a importante discussão da contemporaneidade e que está presente em Educação, cultura e cidadania: comunicações da periferia, com destaque para a cultura enquanto mediadora, num processo de inclusão de todos aqueles cuja voz ainda não se faz ouvir.

A importância do desenvolvimento "da capacidade do jogo, enquanto fator que conduz o indivíduo à ampliação da consciência sobre sua inserção no mundo", o fazer teatral deixando "de ser encarado de modo restrito ao espetacular, passando a ser equacionado em termos das contribuições que oferece para o desenvolvimento do homem, segundo valores como a abertura para a experiência" são as preocupações que regem o artigo de Maria Lúcia de S. B. Puppo, Entre o Mediterrâneo e o Atlântico, uma aventura teatral. Nele, a autora relata sua experiência num trabalho teatral realizado numa cultura distinta da nossa: o Marrocos.

\section{ARTIGO INTERNACIONAL}

Comunicação/educação na formação profissional, de Gabriela Bergomas, amplia o debate. Segundo a autora, "não podemos deixar de considerar 
que a educação inclui e transcende a noção de escolaridade, assim como a comunicação não pode se restringir ao estudo dos meios de comunicação de massa e sua relação com a escola". O campo comunicação/educação está, portanto, num patamar outro, de encontros e desencontros, onde a discussão teoria-prática, as reflexões se fazem fundamentais. No bojo dessa discussão, a autora sugere uma orientação temática, que inclui "aproximações teóricas à articulação da comunicação e educação a partir de uma perspectiva históricocomparativa, análise do contexto e comunicar, aprender e representar a partir de novas tecnologias".

\section{ENTREVISTA}

Jesús Martín-Barbero, um dos mais destacados pensadores latino-americanos do campo da comunicação, é o entrevistado deste número. Em Sujeito, comunicação e cultura, de Roseli Fígaro e Maria Aparecida Baccega, ele nos fala de sua trajetória na Colômbia, assumindo-se como latino-americano. Fala de sua formação teórica, de sua opção pela Comunicação e de como os jovens estão a exigir radicalidade no repensar do papel da escola e das formas de ensino, sempre com a pertinência que o caracteriza.

\section{CRÍTICA}

A divulgação da ciência tem se constituído em desafio permanente. Maior ainda sua complexidade na sociedade midiática, utilizando-se do suporte televisão. Aí se introduz uma vasta gama de complexidades que vão da linguagem à inserção comercial da emissora. Esses são alguns dos pontos que Lucy Barca aborda em Ciência na programação da TV comercial, focalizando o programa Globo Ciência.

\section{DEPOIMENTO}

Telejornalismo, ética e cidadania: esse título traduz o tom do depoimento de Chico Pinheiro, gravado no evento realizado pelo curso de pós-graduação lato sensu Gestão de Processos Comunicacionais, em 12 de novembro de 1998, na ECA. Âncora do telejornal SPTV, da Rede Globo, ele vem imprimindo nova dinâmica ao fazer do jornalismo televisivo. 


\section{EXPERIÊNCIA}

Rosângela A. da S. Grigoletto leva o jornal para a sala de aula e realiza, com ele, um dinâmico trabalho, envolvendo todos os alunos. Em $O$ jornal e a notícia nas aulas de Português, ela nos conta sua experiência com alunos de sétima série de uma escola estadual da Zona Leste de São Paulo. Seu relato nos permite verificar a complexidade do campo comunicação/educação e as possibilidades de crescimento dos alunos quando o enfrentamos.

\section{POESIA}

Manuel Bandeira vai nos levar para o mundo da poesia. Trem de ferro, Sapocururu e $A$ onda nos transportam para um mundo de sons e palavras que se confundem para tornar mais transparente nossa relação com a vida.

\section{SERVIÇOS}

O Museu do Ipiranga, cujo nome oficial é Museu Paulista da USP, é o assunto do artigo da Profa. Mioko Makino. $\mathrm{O}$ acervo e a importância histórica desse espaço cultural são tratados a partir de seu edifício-monumento, das diversas coleções que abriga, bem como de sua significação para a memória nacional. Traz informações que ajudam àqueles que desejarem melhor explorar a riqueza das informações que o museu guarda.

\section{VIDEOGRAFIA}

Neste número, a Profa. Maria Ignês Carlos Magno propõe para a Videografia o tema: ética e meios de comunicação. Através dos filmes Quarto poder, Mera coincidência e Antes da chuva, ela oferece aos leitores uma proposta de trabalho com alunos de primeiro e segundo graus.

\section{BOLETIM BIBLIOGRÁFICO}

O Prof. Ismar de Oliveira Soares na Bibliografia sobre Comunicação e Educação e a Profa. Anamaria Fadul, através da Bibliografia sobre telenovela brasileira, oferecem dados e comentários sobre importantes títulos de livros, artigos, teses e dissertações, para que os leitores possam conhecer mais sobre ambos os temas. 
Resumo: 0 artigo discute como se constitui o discurso da comunicação a partir da transdisciplinaridade. Ou seja, as fronteiras entre os campos de conhecimento são cada vez mais fluidas e, embora mantenham sua especificidade, é preciso vê-las na dinâmica do intercâmbio de saberes, pois a realidade não é compartimentada. Dessa forma, o discurso da comunicação, basicamente construído com a linguagem verbal, constitui-se da conjunção dos discursos da história e da literatura. Com tais características, o discurso da comunicaçāo seleciona, edita e interpreta os fatos do cotidiano, dando um determinado sentido às coisas do mundo. A democratização desse discurso e, portanto, desse ponto de vista passa pela escola que, se ressignificada, pode ser o espaço da transformação da informação fragmentada em conhecimento, o que implica reelaboração e capacidade de seleção. É essa a contribuição que o campo da comunicação/educação pode dar à escola.

Palavras-chave: transdisciplinaridade, discurso da comunicação, democratização, escola, linguagem verbal
Abstract: The article discusses how the communication discourse is constituted based on a trans-disciplinary approach. In other words, the barriers between the fields of knowledge are increasingly more fluid and, although they maintain their specificity, it is necessary to observe them in the view of the knowledge interchange dynamics, since reality is not divided into compartments. Thus, communication discourse, basically built with verbal language, is constituted in the conjunction of the history and literature discourses. With such characteristics, communication discourse selects, edits and interprets daily facts, giving a certain meaning to the things in the world. This discourse has been being democratized, and, therefore, from this point of view it goes through the school where, reinterpreted, it may be the space for the transformation of fragmented information into knowledge, something that implies in re-elaborating the capacity for selection. This is the contribution the communication/education field can make to the school.

Key words: trans-disciplinary approach, communication discourse, democratization, school, verbal language 